\title{
A Pragmatic Account of Anaphora: The Cases of the Bare Reflexive in Chinese*
}

\author{
Lijin Liu \\ Editorial Office of the University Journal, Guangdong University of Foreign Studies, Guangzhou, China \\ Email: Liulj@mail.gdufs.edu.cn
}

\begin{abstract}
Most, if not all, of the existing research on anaphoric constructions containing the bare reflexive 'ziji' in Chinese has been done on a formalist basis and some found in the literature has as it were not given a cogent explanation. The present article, largely based on some discourse and/or pragmatic principles and following a close examination of data drawn from various texts, describes and analyzes its anaphoric uses in two domains: the local and the long-range. The findings suggest that in either case, this bare or simplex reflexive occurs, anaphorically, much more frequently than an alternate complex reflexive or a plain pronoun, which results from the fact that it serves a twofold role, as an alternative to a complex reflexive, on one hand, to minimalize communicative reference and to a pronoun, on the other, to save time for discourse understanding. Such anaphora facts are regulated by a neo-Gricean-like pragmatic principle re the uses of third-person pronouns in Chinese: (a) where the grammar permits the occurrence of both a bare and a complex reflexive, the speaker intending locally bound anaphora tends to use the bare to produce the minimal linguistic information enough to achieve the communicational ends, unless motivated otherwise; (b) where the context permits the occurrence of both a bare reflexive and a pronoun, the speaker intending long-range coreference tends to use the bare reflexive to ease discourse interpretation, unless prevented doing so by other considerations.
\end{abstract}

Index Terms - reflexive, locally bound anaphora, long-range anaphora, pragmatic principle

\section{INTRODUCTION}

Reinhart and Reuland (1993, pp. 658-9) assume a definition of anaphors along the lines of the proposals in Chomsky (1986) and Keenan (1987): Anaphors (of both simplex and complex reflexive type) are referentially defective NPs, which entails that they cannot be used as demonstratives, referring to some entity in the world; and binding may be viewed as the process assigning the content necessary for their referential interpretation. Specifically, anaphors cannot be interpreted independently of the antecedent, because they need to inherit $\Phi$-features (number, gender, person) from their antecedent for that purpose. As further noted in Reinhart and Reuland (1993, p. 685), reflexives differ from pronouns in that they lack $\Phi$-features; although they may preserve person features in many languages (e. g., Dutch 'zich', Norwegian 'seg', Italian 'sè', etc.), they always lack number and gender features. So they do not project an argument that can be interpreted independently. Lack of $\Phi$-features is taken to be the property responsible for their anaphoric nature. Then, 'ziji' in Modern Standard Chinese (hereinafter 'Chinese' for short) is just an anaphor of bare/simplex reflexive type which purely lacks $\Phi$-features. In that case it cannot be entirely interpreted without inheriting those features from its antecedent.

This paper is intended to explain anaphora patterns, analyzing the use of this Chinese reflexive in indirect discourse (cf. Culy 1997, p. 845) ${ }^{1}$ from a pragmatic, particularly the neo-Gricean pragmatic, perspective. Before that, we are supposed to have a discussion of some existing accounts.

\section{EXISTING ACCOUNTS}

In the literature there are a number of accounts of Chinese reflexives, three of which will be sketched out below in light of the difficulties for their analyzing of the reflexive in question.

\section{A. The Thematic Hierarchy}

Xu (1994) argues that Chomsky's (1981, 1982) GB Theory does not give a good explanation of the reference of 'ziji'. Thus he proposes a thematic hierarchy of 'Agent >Experiencer > Theme >Patient', hoping to capture the referential nature of this reflexive. The hierarchy stipulates that a $\Theta$-role (thematic role) on the left is preferable for antecedency to the one coming

\footnotetext{
* This study has been sponsored by Social Sciences Fund of Guangzhou (10Y09) and by the "211" Project (GDUFS211-1) Fund.

${ }^{1}$ Generally, I do not cover first and second person reflexives except in Section II. The reason is that most linguists and scholars tend to take a negative view of the endophoric/anaphoric use of first and second person pronouns including reflexives. For example, Hoeksema and Napoli (1990, p. 422) note that first and second person pronouns are always interpreted deictically. Halliday and Hasan (1976, p. 18) and Halliday and Matthiessen (2004, p. 551) claim that "first and second person pronouns as speech roles of speaker and addressee, are typically exophoric and secondarily anaphoric (speaker and addressee in quoted speech); [...] This type of reference we call EXOPHORA, since it takes us outside the text altogether. Exophoric reference is not cohesive /anaphoric, since it does not bind the two elements together into a text." Fang $(2004$, p. 236) also says that first and second person pronouns in Chinese more often than not have no antecedent within the discourse, so that we do not identify them as co-referential pronouns. Additionally, I will exclude the case where 'ziji' occurs in generic reference, e.g., 'Ziji zuo shi ziji dang' 'Be responsible for whatever you have done.' (Battistella and Xu 1990, p. 223)
} 
after and thus to all the ensuing roles on it. One of Xu's examples is (1).

(1) Hao dongxi dou bei ta ${ }_{1}$ na dao le ziji $i_{1}$ de wuli.

'All the good things were taken into his 1 room by him . $_{1}$ '

According to $\mathrm{Xu}$ (1994), the pronoun ' $t a$ ' 'he', which is not subject, can be regarded as agent, and it is a qualified antecedent of 'ziji'. This seems reasonable. But following Shi and Hu's (2005) analysis, we may still treat ' $t a$ ' 'he' in (1) as subject in structural terms, since the sentence may considered, grammatically, to be a variant of the active sentence, as given in (1)' where ' $t a$ ' 'he' is viewed as an imbedded subject of the Bei-construction (passive sentence construction), outdoing as it were Xu's e-role approach.

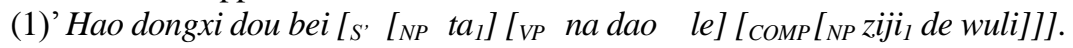

Consider two more examples given in Xu (1994).

(2) Li Xiansheng ${ }_{1}$ de yinmou hai le ziji $i_{1}$.

'Mr Li's ${ }_{1}$ conspiracy did harm to himself ${ }_{1}$.'

(2)' Li Xiansheng ${ }_{1}$ de aoman hai le ziji $i_{1}$.

'Mr Li's ${ }_{1}$ arrogance did harm to himself 1 .'

(3) ?? Weile ziji de liyi, shui ye zudang buliao ta ${ }_{1}$.

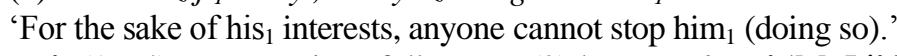

Xu's (1994) argument is as follows. In (2) 'Li Xiansheng' 'Mr Li' is antecedent of 'ziji', because ' $L i$ ' is an agent or indirect agent (i.e., a person who plots a conspiracy). In (3) the verb ' $z u d a n g$ ' 'stop' does not assign ' $t a$ ' 'he' a role of agent, but ' $t a$ ' 'he' can be in fact seen as an indirect agent in semantic terms.

However, the accounts offered by Xu will, we find on second thoughts, run into problems. Granted that 'Li Xiansheng' 'Mr Li' in (2) may be viewed as an indirect agent, there is no reason for treating 'Li Xiansheng' in (2)' (which I specially give in contrast to (2)) as an indirect agent, due to the replacement of 'aoman' 'arrogance' for 'yinmou' 'conspiracy'. In other words, 'Li Xiansheng' 'Mr Li' in (2)' cannot be (indirectly) assigned the same role of agent (or experiencer) as in (2). A second problem is with (3): as 'ziji' in the prepositional phrase cannot be coreferential with ' $t a$ ' 'he' in the object position, this sentence is ill-formed.

Xu's thematic hierarchy, therefore, does not seem to hold water in the presence of the above-stated problems. What makes it worse is that the hierarchy 'Agent-Experiencer-Theme-Patient' does not substantialise in terms of the 'priority order' by which a reflexive picks its antecedent, or of 'constraints' on the coreference between two entities. This results in an undermining of the effectiveness of such an approach in theory and application.

\section{B. The Prominence Computing Algorithm}

$\mathrm{Hu}$ and Pan (2002) point out that the existing non-syntactic approaches to 'ziji' such as Chen (1992), Xu (1994) and Huang (1994) have some limitations in accounting for the reference of it as a long-range reflexive, since they do not take into consideration various factors that may influence the interpretation of reflexives. They argue that the reference of 'ziji' cannot be determined by a single factor. So they've worked out an algorithm for calculating the Prominent NP to be the antecedent of it, based on their idea about multi-factorial determination.

This NP-prominence computing algorithm takes into account several factors, namely syntactic, semantic, discursive /pragmatic. Altogether the algorithm involves six kinds of prominence hierarchy by which to find out the antecedent of a reflexive. These are grammatical, thematic, structural, animacy, person and locality hierarchy, as stated in (4) and some of their combinations are given in (5). ${ }^{2}$

(4) Prominence Hierarchy

a. grammatical hierarchy: [+subject] > [-subject]

b. thematic hierarchy: [+agent] $>$ [-agent] ([+agent] includes [experiencer] and [-agent], [theme])

c. structural hierarchy: [+dominating] $>$ [-dominating]

d. animacy hierarchy: $[+$ animate $]>[$-animate $]$

e. person hierarchy: [+first/second person] $>[-$ first/second person]

f. locality hierarchy: [+local] $>$ [-local]

(5) $[+$ prominence $] \mathrm{NP}$

a. $[+$ subject, +agent $] \quad>\quad$ [+subject, -agent $]$

b. [-subject, +agent] $\quad>\quad$ [-subject, -agent]

c. [+subject, -agent] $>\quad$ [-subject, -agent]

d. [+dominating, +animate] $>\quad$ [+dominating, -animate]

e. [-dominating, +animate] $>\quad$ [-dominating, -animate]

f. [-dominating, +animate] $>\quad$ [+dominating, -animate]

They add a definition of a mechanism for searching the antecedent of 'ziji', as in (6) and of locality, as in (7).

(6) A mechanism of searching the antecedent of 'ziji'.

a. Where there is an NP inside XP, the maximal projection c-commanding the reflexive, and this NP and other NPs inside the maximal projection XP form a NP-sequence, i.e., $\mathrm{NP}=\left(\alpha_{\mathrm{n} . . .}, \alpha_{2}, \alpha_{1}\right)$, then a comparison of [+/-prominence] features, as

\footnotetext{
${ }^{2}$ See Hu and Pan (2002, p. 56) for a detailed description of the combinations of various 'prominence features'.

${ }^{3}$ My translation based on the original in Chinese.
} 
shown above, between (the closest) $\alpha_{i}$ and $\alpha_{i+1}$ is conducted, successively, for ascertaining the NP with [+prominence] as the antecedent of 'ziji'.

b. (omitted, since it will not be referred to.)

c. Once an NP is ascertained as antecedent, its feature [+prominence] will not be annulled.

(7) 'Locality' in (4f) is equal to 'closeness', defined as in Pan (1998): $\alpha$ is closer to the reflexive $X$ than $\beta$, iff the path between $\mathrm{X}$ and the minimal maximal projection dominating $\alpha$ is a true subset of the path between $\mathrm{X}$ and the minimal maximal projection dominating $\beta$.

It would seem right that the 'NP-prominence algorithm' approach is operationally more simple and viable in identifying the antecedent of a long-range reflexive. Take Hu and Pan's (2002) exemplar sentences as in (8).

(8) a. Zhangsan 1 yiwei Lisi $_{2}$ xihuan ziji $i_{1 / 2}$.

'Zhangsan 1 thinks Lisi 2 likes him 1 /himself $_{2}$ '.

b. Zhangsan shuo Lisi $_{2}$ de baogao hai le ziji $i_{1 / 2}$.

'Zhangsan said Lisi's $_{2}$ report did harm to him ${ }_{1} /$ himself $_{2}$ '.

In (8a) the potential antecedent of 'ziji' can be both the locally imbedded and the matrix subject, since one may compare, following (6), the 'prominence' features of the two NPs and find both to be with the feature [+prominence] by (5). In (8b), inside the maximal projection XP c-commanding 'ziji' are three NPs: 'Zhangsan', 'Lisi' and 'baogao' 'report'. First, we compare 'Lisi' and 'baogao' 'report' in terms of the 'prominence' feature: by (5e) 'Lisi' is with the feature [+prominence] and 'baogao' 'report' with [-prominence], so 'Lisi' can be picked as the antecedent. Then, compare 'Lisi' and 'Zhangsan' for deciding on their prominence. By (5b) 'Lisi' continues to retain [+prominence] and thus its antecedentship remains. Similarly, 'Zhangsan' is by (5) with the [+prominence] feature and can be the antecedent of 'ziji' as well.

In actual discourse, however, there are often instances difficult for this 'NP-prominence algorithm' approach to cope with. Example (9) is a case in point.

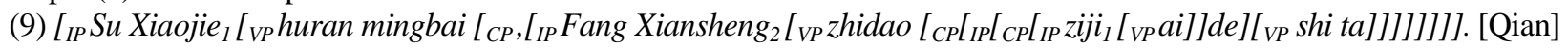

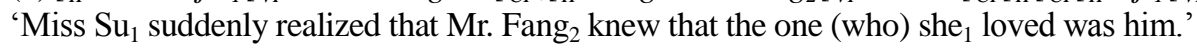

Observing (6) for searching the antecedent of 'ziji' in (9), we may find by (5) both $\mathrm{NP}_{1}$ 'Su Xiaojie' 'Miss Su' and $\mathrm{NP}_{2}$ 'Fang Xiansheng' 'Mr. Fang' to be with the features [+subject, +agent/experiencer] and [+dominating, +animate], so no definitive result can be achieved in these algorithms. Then one needs to make use of (7) to determine which is closer to 'ziji'. Evidently $\mathrm{NP}_{2}$ is found by (7) to carry [+local] information and $\mathrm{NP}_{1}$ [-local], since $\mathrm{NP}_{2}$ is found to be closer to $\mathrm{X}$ ('ziji') when (7) is applied to the two NPs. Therefore $\mathrm{NP}_{2}$ should have been taken to be picked as the antecedent. But unfortunately, the antecedent of 'ziji' in (9) is actually $\mathrm{NP}_{1}$, which shows that the 'prominence computing algorithm' does not hold therein.

\section{The Blocking Effect}

It is observed that studies found in the literature on 'ziji' are frequently concerned with the issue of blocking effect in long-range binding /anaphora, including for instance Battistella (1989), Battistella and Xu (1990), Huang and Tang (1991), Huang (1994), and Hu and Pan (2002). These scholars generally tend to reach the like conclusion that long-range binding of bare 'ziji' to the matrix subject is blocked where a first- or second-person pronoun comes between them and that an intervening third-person pronoun does not prevent embedded 'ziji' from taking as its antecedent a first- or second-person pronoun occurring in the root subject position. This is illustrated by the examples in (10).

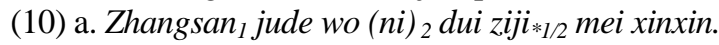

'Zhangsan ${ }_{1}$ thinks that I (you) ${ }_{2}$ have no confidence in himself ${ }_{* 1} /$ myself (yourself) $_{2}$ '

b. Wo $(\mathrm{Ni})_{1}$ jude Zhangsan $_{2}$ dui ziji $\mathrm{i}_{1 / 2}$ mei xinxin.

'I (You) ${ }_{1}$ think Zhangsan ${ }_{2}$ has no confidence in me (you) $)_{1} /$ himself $_{2}$.'

Huang (1994, p. 197), though, provides counterexamples, such as (11), to show that the blocking effect is at least partly pragmatic in nature and a long-range binding interpretation can be occasionally be forced even if there is an intervening firstor second-person pronoun.

(11) Zongtong I $_{1}$ ing wo $_{2}$ zuo zai ziji $i_{1}$ de shenbian.

The president ${ }_{1}$ asked $\mathrm{me}_{2}$ to sit beside (next to) him .' $^{\prime}$

As a reflexive, 'ziji' has to be referentially dependent. In (11), however, it cannot be locally bound by 'wo' 'me' given our knowledge about the world. Consequently, 'ziji' is forced to be long-distance bound to the matrix subject.

Moreover, unlike (10a) there are cases where an intervening third-person pronoun may block long-range binding of 'ziji' to a first- or second-person pronoun used in the matrix clause. This is evidenced by (12) in which 'ziji' cannot be construed as referentially dependent on the subject ' $w o$ ' 'I' or the object ' $n i$ ' 'you', given our knowledge about the background as well as the meaning of the sentence per se.

(12) $W_{1}$ gaosu guo ni $i_{2}$ Zhangsan 3 zai 'Wenge' qijian diaoshi le ziji* $i_{1 * 2 / 3}$.

$\mathrm{I}_{1}$ told you $_{2}$ that Zhangsan 3 hanged $\mathrm{me}_{*_{1}} / \mathrm{you}_{*_{2}} /$ himself $_{3}$ during the Cultural Revolution.'

The evidence seen here leads us to come to interim, inevitable conclusions that the so-called blocking effect in long-distance binding results from mixing up 'zijis' which are distinct in kind and in discourse-type, and this is on the wrong track. As it can be used in any form of person, 'ziji', just like first /second person vs. third person pronoun, has dissimilar uses, namely (situationally) deictic vs. (textually) anaphoric reference (cf. footnote 1). The distinction between pronoun and bare reflexive is that the latter is not manifest in feature or reference-type presentation to the extent that it has to be identified either as anaphorically parasitic on some NP within the text or as deictically dependent on the speaker /addressee outside the text. 
So it can be claimed that there does not seem to be the so-called blocking effect in natural language and it is the proper function of 'ziji' that matters in effecting anaphoric or deictic reference. Deictic reference is situational or at any rate quasi-situational and happens in 'direct speech', and anaphoric reference is text-parasitic and occurs in 'indirect discourse'. (13) and (14) are good examples of deictic reference. In (13) 'ziji' refers to 'addressee', and in (14) it refers to ' $n i$ shushu' 'your uncle', ruling out the blocking effect which should have been engendered by the first-person pronoun 'wo' 'I' (speaker) based on the context thus stipulated.

(13) Yao haohao guanshu ziji. (Dialogue in telefilm)

'(You) should strictly restrain yourself.'

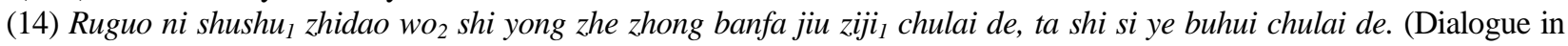
telefilm)

'If your uncle ${ }_{1}$ knew $\mathrm{I}_{2}$ had helped him $_{1}$ out in this way, he would never yet have willingly come out.'

Let us return to the examples in (10). (10a) is narrated in the form of first person and the embedded clause is nothing less than 'direct speech', and 'ziji' refers to the speaker (addressee) and no ambiguity arises in that context. (10b) is like a direct-speech sentence comprising a clause of reported type. So 'ziji' can be understood as both deictic and anaphoric. As a deictic item, 'ziji' points to the speaker (addressee) and may be substituted by 'wo' 'I' (' $n i$ ' 'you'). As an anaphor, 'ziji' is bound by or coreferential with 'Zhangsan', and may be changed into ' $a$ ziji' 'himself'. As matters stand, there are hardly ever sentences like this in naturally occurring discourse. The reference of a linguistic item in an ad hoc context is unique and unambiguous, or else the speaker will surely choose to employ either a first- /second-person pronoun to effect deictic reference or a third-person complex reflexive to yield anaphoric reference accordingly, if there is any possibility that ambiguity arises as in (10b).

To sum up, the argument that for some speakers the presence of an intervening first- or second-person pronoun blocks long-distance of binding of 'ziji' to the matrix subject results from blindly confusing the deictic with the anaphoric use of 'ziji', hence vulnerable.

\section{A Pragmatic Account of the Bare Reflexive "ZiJI" In SENTENCE AND Discourse}

As noted in Section I, being 'bare' (for lack of $\Phi$-features), 'ziji' is an ad hoc anaphor which needs special treatment. In actual discourse 'ziji' is not referentially independent, since it utterly lacks $\Phi$-features. It functions as both a complex reflexive and a pronoun; in other words, it serves as a bound anaphor as well as a long-range anaphor. To see what the relationship of it with a complex reflexive/pronoun would be, let us look at the following analysis of the features of the three types of anaphoric expression, which is adapted on the basis of, but different from, Reinhart and Reuland's (1993, p. 692) analysis.

\begin{tabular}{|l|l|l|l|}
\hline & $\begin{array}{l}\text { Complex reflexive } \\
\text { Pronoun+ziji }\end{array}$ & $\begin{array}{l}\text { Bare reflexive } \\
\text { ziji }\end{array}$ & $\begin{array}{l}\text { Pronoun } \\
\text { ta 'he/she' etc. }\end{array}$ \\
\hline Reflexivizing function, RF & + & $+/-$ & - \\
\hline Referential independence, RI & -4 & - & + \\
\hline
\end{tabular}

Judged from above and also in the spirit of the proposal by Everaert (1991), 'ziji' may be viewed as both a locally bound and a pronominal anaphor. This dual function can be formally expressed as in (15), based on the descriptive summary of its properties.

(15) a. 'ziji' as a bound anaphor

[NP (+RF) ziji (pronoun+ziji)]

b. 'ziji' as a pronominal/long-distance anaphor

[NP (-RF) ziji (pronoun)]

(15) means that where 'ziji' patterns with a complex reflexive, it is referred to as a bound anaphor; where 'ziji' patterns with a pronoun, it is referred to as a long-range anaphor. What is distinctive between 'ziji' and a pronoun is that it lacks $\Phi$-features and must be parasitic on its antecedent, hence marked with the -RI property, whereas a pronoun is characterized by $+\mathrm{RI}$ and may not necessarily have its antecedent in discourse.

Given the properties we have looked at above, I confirm my definition of 'ziji' as (i) bound anaphor and (ii) long-range anaphor, which correspond with 'True anaphor' vs. 'Pseudo-anaphor' (pronominal anaphor) in Pollard and Sag's (1992) terminology. WHERE NECESSARY in the following text, 'ziji' will be marked 'ziji $1_{1}$ ' and 'ziji ${ }_{2}$ ' respectively, designating its two anaphoric uses. ${ }^{5}$

\section{A. Bound Anaphora}

Bound anaphora, something often referred in the literature to as 'coindexation' by UG scholars, is common in syntactic structure. The 'local domain' specified here for the use of the Chinese reflexive would be informal and loose, and will be in a way wider than the governing category /binding domain as defined in the classic Binding Theory (Chomsky 1982, p. 78; see

\footnotetext{
${ }^{4}$ I claim that in Chinese a complex reflexive ('pronoun+ziji') in object position should be taken to have the -RI property and that those in non-object position may have the +RI property and should not be as a whole subsumed under the category of anaphoric expressions. For instance in the sentence 'Shazi si de ta ziji xiao le.' 'He who seemed simple-minded started giggling by himself', ' $t a$ ' 'he' is head and 'ziji' serves as an adverbial element emphasizing 't $a$ ' 'he'.

5 Note that subscripted 'ziji ' and 'ziji ${ }_{2}$ ' when used in the text stand for the two different anaphoric uses of the reflexive at issue, but they have nothing to do with the subscripted reflexives in the examples.
} 
also Haegeman 1994, pp. 192-216). The 'local domain' that should be singled out as having a special status following an analysis of the data collected from various texts and where 'ziji' is locally bound mainly includes three types of syntactic structure: (Co)argument structure, ECM-like structure, and Binding prepositional structure. In these structures 'ziji' has a bound anaphoric use, and it patterns with a complex reflexive and is complementary to a pronoun in reference.

The first type '(Co)argument structure', where 'ziji' is often found to occur as a 'prototypal' bound anaphor, refers to a domain which is undoubtedly subject to Binding Condition A. ${ }^{6}$ In that case 'ziji' is internal argument and bound by external argument, the subject, and the two clausemate co-arguments are coreferential. The sentences in (16) illustrate structure of this type where 'ziji' is locally bound.

(16) a. Ta ${ }_{1}$ kankan ziji $i_{1}$, zai kankan luotuo. [Lao]

' $\mathrm{He}_{1}$ looked at himself ${ }_{1}$, and then looked at the camel.'

b. Keshi, ta kelian le ziji $i_{1}$ [Lao]

'But he 1 took pity on himself ${ }_{1}$.'

The second type 'ECM-like structure' may be regarded as a variant or a sub-category of Coargument structure. A reflexive in such a structure, though not an archetypical argument of the matrix verb, is still obligatorily bound by the matrix subject. This is shown in the examples of (17) where 'ziji' in the ECM-like position takes as its binder the subject of the sentence.

(17) a. $\mathrm{Ta}_{1}$ zhufu ziji ${ }_{1}$ buyao zai bi shang yan. [Lao]

'He $\mathrm{H}_{1}$ told himself $f_{1}$ not to close his eyes once again.'

b. Chang $\mathrm{Hao}_{1}$ zhongyu shi ziji ${ }_{1}$ baituo le 'qian nian lao er'zhi ming. (ex. from the Internet)

'Chang $\mathrm{Hao}_{1}$ finally enabled himself 1 to cast off the name of "No. 2 of the Millennium".'

The third type, so-called 'Binding prepositional structure', refers to prepositional structures/phrases headed by such prepositions as 'wei' 'for', ' $t i$ ' 'for', 'dui' 'to' or the causative preposition ' $b a$ ' in Chinese. These structures frequently, if not always, come after the subject; and as the object of the preposition, 'ziji' is necessarily bound by the subject. So 'ziji' as it is might well be analyzed as 'indirect patient-object' (semantic object), on which the sentential subject as either agent or experiencer has an impact. As illustrative examples take (18):

(18) a. $\mathrm{Ta}_{1}$ wei ziji $i_{1}$ gandao zihao. [Guo]

' $\mathrm{He}_{1}$ felt proud of himself 1 .'

b. $\mathrm{Ta}_{1}$ ti ziji I $_{1}$ taohui le gongdao. [Guo]

' $\mathrm{He}_{1}$ got back the justice for himself ${ }_{1}$.'

c. $T a_{1}$ dui ziji $i_{1}$ shuo, ... [Guo]

' $\mathrm{He}_{1}$ said to himself ${ }_{1}, \ldots$ '

d. Tamen ${ }_{1}$ bu hui ba ziji ${ }_{1}$ fengxian gei laogong he haizi. [Wang L.]

'They ${ }_{1}$ will not devote themselves ${ }_{1}$ to (their) husbands and children.'

Examples (18a-d) show that the prepositions such as ' wei, $t i, d u i, b a$ ' and the like, behave themselves much like a verb, since they imply some function or action of a verb. For instance ' $t i$ ' 'for' actually performs a function as useful as that the verb 'bang' 'help' does, while the causative preposition ' $b a$ ' can fulfill any role just as a causative verb (e.g. 'shi' 'make', ' rang' 'let') does. It follows that for example, (18b) ' $T a_{1}$ ti ziji $i_{1}$ taohui le gongdao' may be changed into ' $\mathrm{Ta}_{1}$ bang ziji $i_{1}$ taohui le gongdao' ' $\mathrm{He}_{1}$ helped himself ${ }_{1}$ get back the justice' without changing the basic meaning of the sentence, and (18d) can be re-expressed as 'Tamen, bu hui shi/rang ziji f fengxian gei laogong he haizi' 'They will not make/let themselves ${ }_{1}$ devoted to their husbands and children'. As to 'dui' 'to', it itself bears a verbal meaning and may be referred to as a 'verbal preposition', evidenced by the fact that it cannot be replaced with the preposition 'duiyu' 'concerning'. So these facts can be said in justification of the argument that the prepositional phrases headed by 'wei, $t i, b a$ ' etc. seem to serve a grammatical function of ECM-like structure, making up a good bound anaphor out of 'ziji' in what we call 'Binding prepositional structure'.

Let me state the principle of the interpretation of 'ziji' as a bound anaphor below:

(19) ' $\mathrm{Ziji}_{1}$ ' is interpreted as bound by or coreferential with the matrix subject, providing that it occurs in a given local (syntactic) domain such as (Co)argument structure, ECM-like structure, Binding prepositional structure and can be analyzed as having a prototypal or hidden (co)argument-relation to the subject.

The rationale underlying the interpretation of ' $\mathrm{ziji}_{1}$ ' in bound-anaphoric use is attributable to what Levinson $(1991,2000)$ calls either the 'B-first' account or the 'A-first' account. For the sake of simplicity, I attempt to base the reading of 'ziji' as bound anaphor on the 'B-first' pragmatic analysis. ' Levinson (1991, 2000), following in the spirit of proposals by Farmer and Harnish (1987) and Huang (1987), develops the 'B-first' account (as an alternative to the earlier 'A-first' account) within the neo-Gricean pragmatic framework. In this analysis the pattern predicted by Condition B is taken to be the basic pattern, out of which the patterns regulated by Conditions $\mathrm{A}$ and $\mathrm{C}$ will then be derived 'for free' by the systematic interaction of neo-Gricean principles of inferential enrichment, viz. Q-, I- and M-inferences.

As noted in Levinson (2000, p. 328), on one hand the stabilized pattern of interpretation where clausemate NPs are preferentially construed as distinct in reference would be thought of as a matter of grammatical stipulation-Condition B (or

\footnotetext{
${ }^{6}$ Chomsky's Binding Condition A: Anaphors must be bound in its governing category (see Haegeman 1994, p. 228).

7 It is certain that the 'A-first' account (Levinson, 1987a/b, 1991, 2000) will also be useful for doing this job, if my handling of 'ziji ' as bound anaphor or 'real anaphor' is on the right track. As Levinson (2000, p. 328) put it, "[...] because the (B-first) account uses the same pragmatic apparatus, there is no theoretical inconsistency between our 'A-first' and what we may call a 'B-first' account." The 'A-first' account simply means that Condition A of the GB Theory is accepted as a rule of grammar and incorporated into the neo-Gricean pragmatic theory of conversational implicature, with Conditions $\mathrm{B}$ and $\mathrm{C}$ being pragmatically predicted respectively by the Q-principle and the Q-principle plus M-inference.
} 
C) as part of Universal Grammar surfacing as an inferential presumption; on the other the core B-like pattern could itself be pragmatically motivated: it is motivated by a pragmatic Disjoint Reference Presumption (DRP) as the basic datum for pronominal anaphora, advanced by Farmer and Harnish (1987). The DRP holds that 'the arguments of a predicate are intended to be disjoint, unless marked otherwise' (Farmer and Harnish, 1987, p. 557). Levinson (2000) relates this pragmatic presumption to his GCI (Generalized Conversational Implicature) framework in its further justification, considering that its origin is left unclear under their account. 'Under a classification of actions of central human interest, agents normally act upon entities other than themselves; the prototypical action — what is described by the prototypical transitive clause - is one agent acting upon some entity distinct from itself. If that is how the world stereotypically is, then an interpretation of an arbitrary transitive sentence as having referentially distinct arguments is given to us by the I[nformativeness]- principle, which encourages and warrants an interpretation of the stereotype' (2000, pp. 328-29).

The argument of the 'B-first' account goes roughly as follows: assuming that the pattern characterized by Binding Condition B is given by the I-principle, ${ }^{8}$ and assuming also that reflexives and lexical NPs are prolix, marked expressions, use of a reflexive or a lexical NP where a pronoun or zero anaphor could have been used will M[anner]-implicate the negation of the interpretation associated with the use of that pronoun or zero anaphor (see for an utter version of the M-principle Levinson 2000, pp. 136-37).

We now turn back to the case of ' $\mathrm{ziji}_{1}$ ' for illustration. Note that ' $\mathrm{ziji}_{1}$ ' is a marked expression and tends to be longer, more morphologically complex than a pronoun (cf. 'ziji' with ' $t a$ ' 'he/she'). ${ }^{9}$ Thus, what 'ziji ${ }_{1}$ ' demonstrates is that the normal, stereotypical scenario associated with a transitive clause does not in fact obtain. In other words, if the stereotype is disjoint reference for arguments, then the M-implicature is (by Horn's 1984 division of pragmatic labor, see Levinson, 2000, p. 331) to the complement of that interpretation, namely to coreference, as illustrated before in the three types of syntactic structure in Chinese where 'ziji' and its antecedent behave in a certain mode of coarguments, a phenomenon that results from M-principle overriding the DRP, or from M-implicatures canceling any rival I-implicatures in accordance with the hierarchy $Q>M>I$. This is how the 'B-first' approach works associated with the use of 'ziji' as a bound anaphor.

\section{B. Long-range Anaphora}

As a long-range anaphor, 'ziji ${ }_{2}$ ' differs greatly from 'ziji ${ }_{1}$ ' in distribution in discourse. One of the main differences between ' $\mathrm{ziji}_{2}$ ' and ' $\mathrm{ziji}_{1}$ ' is that the former does not contrast in reference with a pronoun whereas the latter does. Given that fact, 'ziji ${ }_{2}$ can be viewed in kind as a sort of pronominal anaphor noted above, or non-clause bounded reflexive anaphor (Sells, 1987) or 'locally free reflexive' (Baker, 1995) that may be bound by, or co-referential with, an anteceding element outside the clause and beyond the sentence. For ease of exposition I will consider the anaphoric patterns of 'ziji ${ }_{2}$ ' in two aspects: intrasentential (inter-clausal) anaphora and cross-sentential anaphora.

1. Intrasentential anaphora

Levinson's (1991; 2000, chap. 4) close scrutiny of the anaphoric usage (in particular long-range anaphora) of reflexives shows that long-range anaphors ('ziji ${ }_{2}$ ' is a case in point) and pronouns remain in Q-contrast in logophoricity or subjective point of view, though not in reference. This conclusive observation is theoretically based on what he calls the ' $\mathrm{B}$-then- $\mathrm{A}$ ' account — synthesis of the 'A-first' and 'B-first' accounts.

This synthesis of the 'A-first' plus 'B-first' account involves two pragmatic principles at work, cited below.

(i) The presumption of clausemate coargument disjointness, the DRP, a stereotypical presumption that can be attributed to the I-principle.

(ii) A scalar Q-implicature contrast between reflexive and pronoun, based on the differential semantic strength of the reflexive and the pronoun, the one being necessarily referentially dependent, the other only optionally so; the one suggesting subjective perspective and emphasis, the other lacking such suggestions.

What the synthesis says is that where antecedent and anaphor are coargument clausemates, the I-presumption (i) will ensure there is always a contrast in reference; outside these positions a long-range reflexive is, warranted by the Q-presumption (ii), contrastive in subjective perspective rather than (necessarily) contrastive in reference.

Obviously, as far as ' $\mathrm{ziji}_{2}$ ' is concerned, it is the resultant scalar Q-presumption-based contrast (Horn scale) in logophoricity from the combination of the 'A-first' and 'B-first' analyses that matters much. As a result, a Horn scale formed with 'ziji ${ }_{2}$ ' and ' $t a$ ' 'he /she' by Q-presumption is like <ziji ${ }_{2}[+\operatorname{logophoric}]$, ta [-logophoric]> (the 'referential dependence' property aside) and suggests a contrast in logophoricity. It follows that 'ziji ', used inter-clausally (intrasententially), may well be referred to as 'logophoric pronoun' or 'logophor', after Hagège's (1974) and Clements's (1975) (cf. Sells, 1987) original treatment of some such sort of pronouns in African languages. The antecedent of a logophor must in principle be the one 'whose speech, thoughts, feelings, or general state of consciousness is reported'; hence, logophors appear predominantly with sentential arguments of predicates of communication and mental experience (Sells, 1987, p. 445). 'Ziji ${ }_{2}$ ' (not 'ziji ') in Chinese is precisely an instantiation almost, if not completely, characteristic of a logophoric pronoun so depicted, as is illustrated by the examples in (20)-(22) below. In contrast to ' $t a$ ' 'he/she', 'ziji 2 ' always carries this marked, logophoric information. As a logophor and its antecedent are connected by way of predication, 'ziji ${ }_{2}$ ' is very often found to appear in two types of sentence construction which I refer to as 'logophoric construction' and 'general indirect sentence construction'

\footnotetext{
${ }^{8}$ The related content of the I-principle is that: ... (b) Assume that stereotypical relations obtain between referents /events;... (d) Assume the existence/actuality of what a sentence is about if that is consistent with what is taken for granted (Levinson 2000, pp. 114-115).

9 ' $\mathrm{Ziji}_{1}$ ' is by definition a weaker form of, and has the same anaphoric function as, a complex reflexive.
} 
respectively, though both being indirect in nature. Note that I treat 'ziji ' as a logophor informally at sentence level and do not strictly distinguish its occurrences in the two types of construction, although the one occurrence in logophoric domain may be viewed as 'standard logophor' and the other in general indirect sentence construction as not.

As summarized in Huang (1994, pp. 187-88), logophoric domains in Chinese are usually triggered by logophoric verbs such as speech verbs: 'shuo' 'say', 'gaosu' 'tell', 'baogao' 'report', 'biaoshi' 'express', 'zhichu' 'point out'; epistemic verbs: 'xiangxin' 'believe', 'renwei' 'think', 'huaiyi' 'suspect'; perceptive verbs: 'kanjian' 'see', 'tingdao' 'hear', etc. A logophor invariably comes in an object clause introduced by such a verb and picks the matrix subject as its antecedent, in whatever syntactic slot it occurs. Consider the examples in (20):

(20) a. Budao yi dun fan shi, Xianglin Sao ${ }_{1}$ bian huilai le, gaoxing side dui Si Shen ${ }_{2}$ shuo, ziji $i_{1}$ yijing zai tudi miao juan le menkan. [Lu]

'In less than a meal's duration of time, Sister Xianglin ${ }_{1}$ then returned and said, as if cheerfully, to Fourth Aunt that she $_{1}$ had already donated to the village temple money for "making a threshold for atonement".'

b. Sun $\mathrm{Li}_{1}$ zhidao $\mathrm{ta}_{2}$ zheyang zuo shi hao rang ziji likai ta. [Wang Y.]

'Sun $\mathrm{Li}_{1}$ knew that what he did was to let her $_{1}$ leave him simply.'

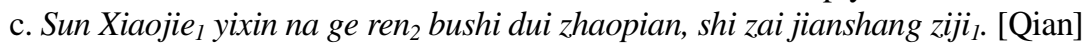

'Miss $\operatorname{Sun}_{1}$ suspected what that $\operatorname{man}_{2}$ was doing was not checking her photo but appreciating her ${ }_{1}$.'

The examples of (20) comprise 'standard' logophoric contexts and describe some reported speech events. In this discourse setting the reflexive, whatsoever grammatical role it assumes (in (20a) it serves as the embedded subject, in (20b) an element of the ECM clause and in (20c) the object of 'jianshang' 'appreciate' in the embedded clause), invariably takes as its antecedent the root subject which represents the sentence-internal protagonist.

'General indirect sentence constructions' are non-logophoric constructions, those without logophoric verbs triggering logophoric domains as in (20). But still such structures are 'subject-oriented': the matrix subject being antecedent of the reflexive in an overwhelming majority of cases; occasionally with its sub-constituent (modifier) being antecedent, which is forced to happen by semantic and contextual constraints but does not in principle violate the general antecedent-anaphor linkage pattern - antecedent occurring in the subject position vs. anaphor (reflexive) in the predicate. Let (21) and (22) be such examples: 'ziji' picks as its antecedent the subject in (21) and in (22) the modifier of the subject due to the head (subject) being inanimate.

(21) a. Jiashi yi ge fan xiao gui de nü xuesheng zhang de hen piaoliang,

Gao Xiaozhang ${ }_{1}$ zhiyao ta ${ }_{2}$ xiang ziji $i_{1}$ qiuqing rencuo, yexu hui congkuan chufen. [Qian]

'If a girl student who disobeyed school rules looked very beautiful, Principal $\mathrm{Gao}_{1}$ would perhaps give her lenient treatment as long as she 2 pleaded with and apologized to him ${ }_{1}$.'

b. Danshi ta $a_{1}$ hai neng kongzhi ziji $i_{1}$ de ganqing. [Xia]

'But she ${ }_{1}$ could still control her ${ }_{1}$ emotion.'

(22) a. $\mathrm{Ta}_{1}$ de yan ${ }_{2}$ fangfu shi lao kan zhe ziji $i_{1}$ de xin. [Lao]

'His eyes $_{2}$ seemed to be always looking at his ${ }_{1}$ heart.'

b. Ta ${ }_{1}$ de biaoqing he hanyi $i_{2}$ xia de Fang Hongjian bu gan kai kou, zhi aohui ziji $i_{1}$ qifen zhuang de tai xiang le. [Qian]

'Her facial expression and implication $_{2}$ so frightened Fang Hongjian that he did not dare say a single word; and she only regretted she ${ }_{1}$ had pretended to be too truly angry.'

In this section we have seen two types of sentence construction where 'ziji' functions to effect intrasentential (long-range) anaphora, encouraged by the Q-principle-based contrastive implicature in logophoricity which arises from the combination of the 'A-first' and the 'B-first' account (Levinson, 2000). The examples in (20)-(22) indicate that long-range reflexive 'ziji', albeit serving syntactic purposes of a wide variety, behaves in some consistent way: it definitely comes in the predicate, frequently with the root subject and occasionally with its sub-constituent as the antecedent.

2. Cross-sentence anaphora

So far, much less work seems to have been exclusively done on 'ziji' used cross-sententially in Chinese. As a special long-range anaphor occurring cross-sententially, 'ziji' is regularly more distant from its antecedent than in the intrasentential (inter-clause) case, in terms of syntactic structure. The above-said Q-presumption-based contrastive implicature in logophoricity, therefore, does not seem to capture cross-sentential anaphora patterns in actual discourse. To account for anaphoric patterns of this type, we can easily adjust and extend that resulting apparatus from the interaction of neo-Gricean pragmatic principles, which is to be attempted soon. We first of all turn to the analyses by Zribi-Hertz (1989) and Baker (1995), since they are useful for tackling the issue of cross-sentential anaphora in Chinese.

Zribi-Hertz (1989) offers a corpus-based survey of occurrences of English reflexive pronouns which are shown to be largely against Chomsky's Binding Principle A in a productive way. Her data suggests that English reflexives (for instance 'himself') have been sub-classified into two sets: emphatic vs. non-emphatic reflexive. Based on the data gathered for her study she (1989, sec. 4) proves that nonemphatic reflexives should strictly respect Binding Principle A which is decomposed into six distributional constraints and that emphatic reflexives which might violate the c-command or binding constraints may have no antecedent at all (be actually free) within their sentence and may be bound beyond the minimal governing category, hence called LDB (long-distance bound) reflexives. Zribi-Hertz (1989) proposes a discourse principle justifying the long-distance binding of LDB reflexives, as summarized in (23).

(23) A discourse principle regulating LDB reflexives: 
In English a reflexive pronoun may occur in violation of some stipulation with respect to the Binding Principle A, iff it refers back to the Minimal Subject of Consciousness.

The concept 'Subject of Consciousness' (SC) is defined as a category of discourse grammar, a semantic property assigned to a referent whose thoughts or feelings are conveyed by a portion of discourse. The SC is then understood along the lines as stated in (24).

(24) The Minimal SC (for a given pronoun in discourse) = either (a) or (b):

a. the nearest available NP (or combination of NPs) which occurs in discourse to the left of the pronoun and is read as logophoric (referring back to the Minimal SC);

b. the speaker or the addressee (or a group including either one or both), whether or not explicitly mentioned in discourse.

Baker (1995), however, questions the truth of Zribi-Hertz's argument that there is this strong correlation between SC and emphatic reflexive. As Baker (1995, pp. 66-67) put it, as regards logophoricity one indeed finds (in novels and other works) many examples where an LFR (locally free reflexive) refers to an SC, but he also finds (in some novels) many examples of LFRs that are clearly not logophoric; in some of them the SC is the omniscient narrator while in others it is a character different from that denoted by a reflexive. As regards emphasis, he notes that the typical LFR occurs in a situation in which the character it refers to is being contrasted with some one or more other characters. Given such observations, Baker proposes two conditions dominating English intensive NPs: (i) contrastiveness and (ii) discourse prominence, and argues that LFRs should be best analyzed as intensified non-nominative pronouns subject to the 'contrastiveness' as well as the 'discourse prominence' requirement.

As far as the Chinese reflexive in question is concerned, it seems that either Zribi-Hertz's principle or Baker's proposal alone will not be thoroughly in order, but some of their proposals are pretty helpful for our discussion. For one thing, in Chinese 'ziji' as a long-range reflexive is nonemphatic, and Zribi-Hertz's principle is mainly intended to regulate LDB reflexives which are taken to be emphatic. ${ }^{10}$ In addition, 'speaker' or/and 'addressee' is/are regarded as a case of the SC, but I exclude both in this article, since they generally have no anaphoric function (see footnote 1). For another, 'ziji' can often occur in nominative case in Chinese discourse, contrary to Baker's (1995) treatment of LFRs in English as intensified 'non-nominative pronouns'. Yet, I would believe that both of them have contributed insightful thoughts to the interpretation of Chinese reflexive. Zribi-Hertz's treatment of 'the nearest available NP' as a 'minimal SC', for one, may bring to light a large set of occurrences of 'ziji' in discourse which have not been so directed by any other approach. And the 'discourse prominence' or 'contrastiveness' requirement proposed by Baker also captures most of the cases where 'ziji' appears as a cross-sentential /discourse anaphor: our data shows that the entities referred to by 'ziji' tend to be more prominent and marked in discourse in contrast to those denoted by ordinary pronouns.

Given the situations so depicted, we follow the lines of the relevant proposals by both Zribi-Hertz (1989) and Baker (1995) and attempt to formulate a discourse principle governing 'ziji' used in cross-sentential anaphora pattern. However, we need to advance beforehand the notion of 'D-logophoricity' to cover the occurrence of 'ziji' different in nature than that characterized by 'logophoricity': the term 'D-logophoricity' is particularly invented here and defined as the quality of the discourse-internal protagonist's point of view associated with the use of 'ziji', in view of the fact that the concept 'logophoricity' as it stands cannot capture the cases of cross-sentential anaphora, especially where 'ziji' occurs as the subject of a sentence. ${ }^{11}$

I propose in (25) a discourse/pragmatic principle governing the use of 'ziji' in cross-sentential anaphora pattern.

(25) As a cross-sentential reflexive, 'ziji' occurring in a given portion of discourse is interpreted as referring back to the Minimal Discourse-internal Protagonist.

'Minimal Discourse-internal Protagonist' (MDP for short), to be frank, may be seen as a partial clone of Zribi-Hertz's 'Minimal Subject of Consciousness', notwithstanding there are some dissimilarities in nature between the two concepts. Similarly, MDP is generally treated as some referent whose thoughts or feelings are reported by part of a discourse. For an occurrence of the reflexive in discourse, the MDP is to be understood according to the definitions stated in (26).

(26) The MDP is instantiated and construed as the closest matrix subject NP (including a pronoun) which is prominently available and prior to the reflexive in discourse, and is read as D-logophoric (cross-sententially coreferential with 'ziji').

We can now account for cross-sentence anaphoric patterns in actual discourse. To illustrate, take (27)-(29):

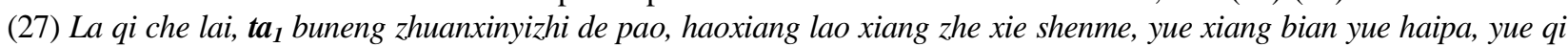
bubing. Jiaruo lao zheme xiaqu, jishi cai neng mai shang che ne? Weishenme zheyang ne? Nandao ziji hai suan ge bu yaoqiang de? (MDP $=t a_{l}$ 'he'/Xiangzi) [Lao]

'During the course of rickshaw-pulling, he ${ }_{1}$ could not concentrate his attention on running, as if always pondering over something; the more he pondered, the more he was scared and indignant over the injustice. If he always continued like this, when could he afford to buy a rickshaw? Why like this? Wasn't he $\mathbf{1}_{\mathbf{1}}$ counted as excellent enough yet?'

(28) $\boldsymbol{T a}_{1}$ xiang Han Хиеуu de wenping jia bu jia, guan ta ganme. Keshi, you yi jian shi, Han Taitai jiang Niu Yue de shihou, Han Хиеуи dui ta zиo ge yanse, zhe yanse meiyou taoguo ziji ${ }_{1}$ de yan, dangshi jiи you yi ge yinxiang, fangfu touting dao renjia beihou jiang ziji $i_{1}$ de hua. (MDP=Ta ${ }_{l}$ 'He') [Qian]

'He $\mathbf{H}_{1}$ thought that as for whether or not Han Xueyu's diploma was false, for what he cared about it. But there happened one thing: at the time when Mrs Han talked about New York, Han Xueyu tipped her a wink; this wink did not escape his $\mathbf{1}_{\mathbf{1}}$ eyes and at that moment he instantly had an impression that he seemed to overhear what others said of him $\mathbf{1}_{\mathbf{1}}$ behind his backs.'

\footnotetext{
${ }^{10}$ Generally, only a complex reflexive in Chinese like 'ta ziji' 'himself/herself' can be on a par with an emphatic reflexive in English.

11 'D-logophoricity', where 'D' stands for 'discourse-internal', is thus coined after 'logophoricity'.
} 
(29) Hongjian ${ }_{1}$ qinggan xiang ge xuanwo. Ziji ${ }_{1}$ mei qian dao, keyi fangxin. Dan tingshuo Sun Xiaojie he pangren hao, you cixin nanshou. Ziji $i_{1}$ bingwei ai shang Sun Xiaojie, heyi bu yuan ta gen Lu Zixiao yaohao? (MDP=Hongjian ${ }_{1}$ ) [Qian]

'Hongjian's $\mathbf{s}_{1}$ feeling seemed an eddy. $\mathbf{H e}_{1}$ was not involved in it, and could feel relieved. But when hearing that Miss Sun was on good terms with others, he was also in great pain. $\mathbf{H e}_{\mathbf{1}}$ did not love Miss Sun; why not hope that she was friends with Lu Zixiao?'

Let's analyze how the reflexive 'ziji' performs a cross-sentence anaphoric role under the viewpoint of the MDP in (27)-(29). First, it is clearly seen in (27) that there is only the pronoun ' $t a$ ' 'he' (referring to the protagonist 'Xiangzi') which qualifies by (26) for the MDP, and it is naturally understood as D-logophoric associated with the use of 'ziji'. Then in (28) there are five potential antecedent NPs, occurring sequentially as: 'Ta' 'he', 'Han Xиеуu', 'Han Taitai' 'Mrs Han', 'Han Хиеуи', ' $t a$ ' 'she'; and 'ziji' (used twice) does not refer to 'ta' 'she'/ 'Han Taitai' 'Mrs Han' or 'Han Xuеyu' in the same sentence or 'Han Хиеуu' embedded in the nearer object clause of the first sentence, but refers to 'Ta' 'he' (i.e. 'Hongjian') in the very beginning of the first sentence which remains prominent in the discourse. Finally in (29), apparently, the subject of the first sentence (also topic of the discourse) 'Hongjian' is the MDP referred to by 'ziji' used in the subject positions of the second and forth sentences. Besides, it seems to show us that the first, topical sentence serves as what may be called the 'minimal D-logophoric trigger' in such a larger portion of discourse, much like the use of a 'logophoric verb' such as 'shuo' 'say' or ' $z$ hidao' 'know' etc. as in the examples of (20).

I base these anaphora patterns on some theoretic presumption which results from the neo-Gricean pragmatic accounts, noted before. On the basis of the combination of I-presumption and Q-presumption, just as we had the Q-presumption-based contrast (Horn-scale contrast) in logophoricity resulting from 'A-first' plus 'B-first' approach, we have a like contrastive Horn scale, viz. a scalar Q-implication-based contrast in D-logophoricity. Specifically, as can be seen from (27)-(29), the use of 'ziji' as a cross-sentence anaphor, also known as 'D-logophor' after 'logophor', may be taken to be promoted by contrast to the use of a pronoun, and the two form a Horn scale <ziji [+D-logophoric], PRONOUN (e.g. 'ta') [-D-logophoric]>. This scale denotes that there is a contrast between the strong assertion $(\mathrm{A}(S))$ (=the one with a reflexive) and the weak assertion $(\mathrm{A}(W))$ (=the one with a pronoun) in terms of D-logophoricity, to the effect that the reflexive is obligatorily D-logophoric, whereas the pronoun not so. In each of the examples of cross-sentence anaphora provided above, the speaker used the strong 'reflexive', making clear that he/she intended to construct a cross-sentence anaphoric pattern which is subject to the principle stated in (25). As a D-logophor, 'ziji' is then held to be in perspective related to its antecedent: it occurs within the perspective of the MDP (the antecedent).

\section{Summary}

Thus far, I have provided various examples of sentence and discourse structure to indicate that the reflexive 'ziji' has at least a twofold function: on one hand it is used to serve the purpose of composing locally bound anaphora patterns; on the other, it serves to produce long-range anaphoric reference at the level of either intra- or cross-sentence structure. This is the outcome of the nature of this reflexive: for lack of $\Phi$-features, 'ziji' has to be parasitic on its antecedent and the antecedent is supposed to occur within the discourse. In summary, I give the details of the anaphoric properties of 'ziji' in Table 1.

TABLE 1

THE ANAPHORIC PROPERTIES OF 'ZIJI'

\begin{tabular}{|c|c|c|c|c|c|c|c|c|c|c|}
\hline \multirow[t]{2}{*}{ Anaphors } & \multicolumn{3}{|c|}{ Domain } & \multicolumn{3}{|c|}{ How related to antecedent } & \multicolumn{3}{|c|}{$\begin{array}{c}\text { In what way contrasted with } \\
\text { pronoun }\end{array}$} & \multirow[t]{2}{*}{ Remarks } \\
\hline & LOC & IS & $\mathrm{CS}$ & $\mathrm{ARG}$ & PRE & PER & REF & LOG & D-LOG & \\
\hline $\mathrm{ziji}_{1}$ & + & - & - & + & - & - & + & - & - & $\begin{array}{l}\text { As a weak form of } \\
\text { complex reflexive }\end{array}$ \\
\hline $\mathrm{ziji}_{2}$ & - & + & + & - & + & + & - & + & + & $\begin{array}{c}\text { As a strong form of } \\
\text { pronoun }\end{array}$ \\
\hline
\end{tabular}

Notes: $\mathrm{LOC}=$ (informally) local domain; $\mathrm{IS}=$ intrasentence; $\mathrm{CS}=$ cross-sentence; $\mathrm{ARG}=(\mathrm{co})$ argumenthood; $\mathrm{PRE}=$ predication; $\mathrm{PER}=($ discourse-internal protagonist's) perspective; $\mathrm{REF}=$ reference; $\mathrm{LOG}=$ logophoricity; $\mathrm{D}-\mathrm{LOG}=\mathrm{D}$-logophoricity.

Table 1 presents general information on the anaphoric characteristics of this reflexive. As a bound anaphor, 'ziji ${ }_{1}$ ' is restricted to the local domain - some syntactic structures, as informally defined in Section 3.1. It is related to the antecedent by way of (co)argumenthood in a certain mode: it is bound in such structures, since reflexive and antecedent may be analyzed as either prototypical (syntactic) or hidden (semantic) clausemate co-arguments. It is used as a weak form of complex reflexive and is complementary with a pronoun in reference. As a long-range anaphor, 'ziji ${ }_{2}$ ' allows its antecedent outside the 'local domain': it allows the antecedent to occur beyond both the clause and the sentence. As it can be viewed as pronominal distinct in kind from ' $\mathrm{ziji}_{1}$ ', 'ziji ${ }_{2}$ ' serves as a strong form of pronoun, and contrasts with a pronoun in logophoricity, as in the case of intrasentence (inter-clause) anaphora, or in D-logophoricity, as in the case of cross-sentence/discourse anaphora. Intrasententially, the reflexive is connected with its antecedent by way of predication: it definitely comes in the predicate and its antecedent in the subject; cross-sententially, the reflexive is absolutely within the perspective of the antecedent (the MDP).

\section{ADDITIONAL FACTS AND CONCLUSION}

The anaphoric uses of 'ziji' differ widely in discourse. To find out about its overall, different uses, I have analyzed the distributional data of its anaphoric configurations in two noted Chinese novels 'Wei Cheng' 'Fortress Besieged' (Qian, 
1946/1980) and 'Luotuo Xiangzi' 'Camel Xiangzi' (Lao, 1936/1982). In an analysis of 852 examples in respect of 'ziji', extracted from the novels, I have found that only 85 occur in the case of bound anaphora, accounting for proximately $10 \%$ of the examples (85/852), while as much as $58 \%$ of the examples (498/852) occur in intrasentence (inter-clause) anaphoric pattern and $32 \%(269 / 852)$ in cross-sentential anaphora, the total percentage of the long-range anaphoric occurrences being overwhelmingly high-90\%! In addition, I have a comparison of the instantiations of 'ziji' vs. an alternative complex reflexive and an alternative pronoun, in order to discover the contrastive ratios in frequency between these distinct items ${ }^{12}$. The data reveals that in the corpus the percentage of the occurrences of ' $\mathrm{ziji}_{1}$ ' is $93.4 \%$ in striking contrast with $6.5 \%$ of the occurrences of the complex reflexive, in the case of bound anaphora, while $77 \%$ of the uses of 'ziji ${ }_{2}$ ' vs. $23 \%$ of the uses of the pronoun are found to be in the case of long-range anaphora at sentence level. ${ }^{13}$

Notwithstanding that I confined this cursory, data-based survey to the aforementioned novels, I believe the general findings would not have been much altered concerning the uses of bare vs. complex reflexive and pronoun in Chinese, even if a larger corpus had been covered in such a study. It follows that in Chinese the uses of the (third-person) bare reflexive 'ziji' as a (locally) bound anaphor are of low frequency while those of 'ziji' as a long-range anaphor are of high frequency, and in any case the proportion of 'ziji' in discourse is much higher than either that of an alternative complex reflexive or that of an alternative pronoun.

Given the two distinct functions it serves, 'ziji' plays an indispensable role in improving communicative reference. To put it plainly, as a bound anaphor, 'ziji' is in a position to serve as a weak form of complex reflexive to economize on discourse production on one hand; as a long-distance anaphor, it serves as a strong form of pronoun to ease discourse understanding on the other. The survey conducted in this study, therefore, has led to the conclusion that there prevails in discourse production in Chinese a neo-Gricean-like pragmatic principle facilitating the achievement of communicational ends, as stated in (30), which is revised from Liu (2008).

(30) A pragmatic principle regarding the use of third-person pronouns in Chinese:

a. Where the grammar permits the occurrence of both a bare and a complex reflexive, the speaker intending locally bound anaphora prefers to use the bare (ziji $\left.{ }_{1}\right)$ to produce the minimal linguistic information enough to achieve the communicational ends, unless motivated otherwise (e.g., motivated to suggest "emphasis").

b. Where the context permits the occurrence of both a bare reflexive and a pronoun, the speaker intending long-range coreference prefers to use the reflexive (ziji $\left.{ }_{2}\right)$ to ease discourse interpretation, unless prevented doing so by other considerations (e.g., avoiding suggesting the "protagonist's point of view").

It is particularly worth noting that (30) may be taken upon the whole to count as a practical approach actualizing the relevant, core theoretical principles of the neo-Gricean framework of conversational implicature. For as can be seen from (30), we can, no doubt, owe (30a) immediately to the I-principle and (30b) to the Q-principle (Levinson, 2000) ${ }^{14}$.

\section{APPENDIX SOURCES OF TEXTUAL EXAMPLES}

[Guo] Guo Guangyun. 2004. 'Wo Gao Cheng Weigao' 'My story of suing Cheng Weigao' (newspaper serial). Yangcheng Evening Paper (issues in April, 2004).

[Lao] Lao She. 1936 /1982. Luo Tuo Xiang Zi 'Camel Xiangzi' (also translated into Rickshaw Boy) (extracted from the Chinese literature website: www.chinawx.com).

[Lu] Lu Xun. 1995. 'Zhu Fu' 'Blessings'. In the Complete Works of Lu Xun. Beijing: Chinese Literature Press.

[Qian] Qian Zhongshu. 1946 /1980. Wei Cheng 'Fortress Besieged'. Beijing: Chinese Literature Press (also: www. chinawx. com).

[Wang L.] Wang Lili. 2004. 'Shanghai Nü Ren' 'Women from Shanghai'. Yangcheng Evening Paper (16 January, 2004).

[Wang Y.] Wang Yi. 2004. 'Bu Gui Zhang Fu Zao Che Huo, 15 Zai Di Yu Hun Yin Wu Chu Tao' 'Her lecherous husband disabled in a traffic accident, she cannot escape her 15-year hell-marriage.' Family (a Chinese magazine) 4, 30-32.

[Xia] Xiamen University Corpus. http://www.xmuoec.com/gb/hanyu/hanyu/data/corpus/index.htm.

\section{REFERENCES}

[1] Baker, C. L. (1995). Contrast, discourse prominence, and intensification, with special reference to locally free reflexives in British English. Language, 71 (1), 63-101.

[2] Battistella, E. (1989). Chinese reflexivization: A movement to INFL approach. Linguistics, 27, 987-1012.

[3] Battistella, E. \& Xu, Y. H. (1990). Remarks on the reflexive in Chinese. Linguistics, 28, 205-240.

[4] Chen, P. (1992). The reflexive 'ziji' in Chinese: Functional vs. formalist approaches. In Lee, T. (ed.). Research on Chinese Linguistics

\footnotetext{
${ }^{12}$ An alternative complex reflexive refers to one which overlaps in distribution with 'ziji ' (bound anaphor) and an alternative pronoun refers to one which overlaps with 'ziji ' ' (long-range anaphor). I give an example for each of them as in (i) and (ii), where coreference is marked with boldfacing. (i) 'Xiangzi kan wan le ta ziji ( $\left.\approx z i j i_{1}\right)$, hui tou kan le kan luotuo.' 'Xiangzi had looked at himself; then turned round and took a look at the camel.' (ii) 'Xia Taitai buhui liu zhe ge zhidao ta ( $\left.z i j i_{2}\right)$ de lishi de puren.' 'Mrs Xia would not keep on a maid who knew about her life story.' Note that in (i) 'ta ziji' 'himself' differs in a way from 'ziji ${ }_{1}$ ' in that it carries additional information of "emphasis" and that in (ii) ' $t a$ ' 'her' differs from 'ziji ${ }_{2}$ ' in that the latter suggests obligatory logophoricity while the former does not, though each of the two pairs is not distinct in reference.

${ }^{13}$ Constrained by operational difficulties, I did not compare the use of 'ziji ' ' with that of the pronoun in the case of cross-sentence anaphora in the corpus.

14 Levinson's (2000, p. 114) I-principle: Speaker's maxim: say as little as necessary, i.e. produce the minimal linguistic information sufficient to achieve your communicational ends, and Levinson's (2000, p. 76) Q-principle: Speaker's maxim: Do not provide a statement that is informatively weaker than your knowledge of the world allows, unless providing a strong statement would contravene the I-principle.
} 
in Hong Kong. Hong Kong: The Linguistic Society of Hong Kong.

[5] Chomsky, N. (1981). Lectures on Government and Binding. Dordrecht: Foris.

[6] Chomsky, N. (1982). Some Concepts and Consequences of the Theory of Government and Binding. Cambridge, Mass.: MIT Press.

[7] Chomsky, N. (1986). Knowledge of Language: Its Nature, Origin, and Use. New York: Praeger.

[8] Culy, C. (1997). Logophoric pronouns and point of view. Linguistics, 35, 845-859.

[9] Everaert, M. (1991). Contextual determination of the anaphor/pronominal distinction. In Koster, J. \& Reuland, J. (eds.). Long-distance Anaphora. Cambridge: CUP, 283-321.

[10] Fang, Jingmin. (2004). The reference of third-person pronoun and its contextual constraints in Mandarin Chinese. Contemporary Linguistics, 3, 236-247.

[11] Farmer, A. \& Harnish, M. (1987). Communicative reference with pronouns. In Verschueren, J. \& Bertuccelli-Papi, M. (eds.). The Pragmatic Perspective. Amsterdam: John Benjamins, 547-564.

[12] Haegeman, L. (1994). Introduction to Government and Binding Theory. Oxford: Blackwell.

[13] Halliday, M. A. K. \& Matthiessen, M. I. M. (2004). An Introduction to Functional Grammar (3rd edition). London: Arnold.

[14] Halliday, M. A. K. \& Hasan, R. (1976). Cohesion in English. London: Longman.

[15] Hoeksema, J. \& Napoli, D. J. (1990). A condition on circular chains: A restatement of i-within-i. Linguistics, 26, $403-424$.

[16] Huang, C.-T. J. \& Tang, C.-C. J. (1991). The local nature of the long-distance reflexive in Chinese. In Koster, J. \& Reuland, E. (eds.). Long-distance Anaphora. Cambridge: CUP, 263-282.

[17] Huang, Y. (1987). Zero Anaphora in Chinese: Towards a Pragmatic Analysis. Cambridge College Research Fellowship Competition Dissertation.

[18] Huang, Y. (1994). The Syntax and Pragmatics of Anaphora: A Study with Special Reference to Chinese. Cambridge: CUP.

[19] $\mathrm{Hu}$, Jianhua \& Pan, Haihua. (2002). NP prominence and the Chinese reflexive 'ziji'. Contemporary Linguistics, 1, 46-60.

[20] Keenan, E. (1987). On semantics and the binding theory. In J. Hawkins (ed.). Exploring Language Universals. Oxford: Blackwell.

[21] Levinson, S. C. (1987a). Minimalization and conversational inference. In Verschueren, J. \& Bertuccelli-Papi, M. (eds.). The Pragmatic Perspective. Amsterdam: John Benjamins, 61-129.

[22] Levinson, S. C. (1987b). Pragmatics and the grammar of anaphora: A partial pragmatic reduction of binding and control phenomena. Journal of Linguistics, 23, 379-434.

[23] Levinson, S. C. (1991). Pragmatic reduction of the binding conditions revisited. Journal of Linguistics, 27, 107-161.

[24] Levinson, S. C. (2000). Presumptive Meanings: The Theory of Generalized Conversational Implicature. Cambridge, MA: MIT.

[25] Liu, L. (2008). The anaphoric function of the reflexive 'ziji' in modern Chinese. Journal of Foreign Languages, 1, 36-44.

[26] Pan, H. (1998). Closeness, prominence, and binding theory. Natural Language and Linguistic Theory, 16, 771-815.

[27] Pollard, C. \& Sag, I. A. (1992). Anaphors in English and the scope of Binding Theory. Linguistic Inquiry, 23 ( 2), $261-300$.

[28] Reinhart, T. \& Reuland, E. (1993). Reflexivity. Linguistic Inquiry, 24 (4), 657-720.

[29] Sells, P. (1987). Aspects of logophoricity. Linguistic Inquiry, 18, 445-479.

[30] Shi, Dingxu \& Hu, Jianhua. (2005). The syntactic status of 'bei'. Contemporary Linguistic, 3, 33-43.

[31] Xu, Liejiong. (1994). The antecedent of 'ziji'. Journal of Chinese Linguistics, 21,123-141.

[32] Zribi-Hertz, A. (1989). Anaphor binding and narrative point of view: English reflexive pronouns in sentence and discourse. Language, 65 (4), 695-727.

Lijin Liu received his MA degree in linguistics and applied linguistics from Guangdong University of Foreign Studies, China in 1992.

$\mathrm{He}$ is Professor of English and CLAL (Center for Linguistics and Applied Linguistics) researcher as well, and is currently working for the Journal of Guangdong University of Foreign Studies. His main research interests include pragmatics and discourse analysis, in particular study of anaphora/reflexivization in discourse from a functional/pragmatic perspective. 